\title{
Comparison of DMSP cross-track ion drifts and SuperDARN line-of-sight velocities
}

\author{
R. A. Drayton ${ }^{1}$, A. V. Koustov ${ }^{2}$, M. R. Hairston ${ }^{2}$, and J.-P. Villain ${ }^{3}$ \\ ${ }^{1}$ Institute of Space and Atmospheric Studies, University of Saskatchewan, Saskatoon, Canada \\ ${ }^{2}$ William B. Hanson Center for Space Sciences, University of Texas at Dallas, USA \\ ${ }^{3}$ Centre National de la Recherche Scientifique, Orleans, F-45045, France
}

Received: 1 March 2005 - Revised: 1 June 2005 - Accepted: 20 June 2005 - Published: 14 October 2005

\begin{abstract}
Cross-track ion drifts measured by the DMSP satellites are compared with line-of-sight SuperDARN HF velocities in approximately the same directions. Good overall agreement is found for a data set comprising of 209 satellite passes over the field of view of nine SuperDARN radars in both the Northern and Southern Hemispheres. The slope of the best linear fit line relating the SuperDARN and DMSP velocities is of the order of 0.7 with a tendency for SuperDARN velocities to be smaller. The agreement implies that the satellite and radar data can be merged into a common set provided that spatial and temporal variations of the velocity as measured by both instruments are smooth.
\end{abstract}

Keywords. Ionosphere (Ionospheric irregularities; Plasma convection; Auroral ionosphere)

\section{Introduction}

Observations of ionospheric plasma convection at high latitudes is important for understanding various processes occurring in the Earth's magnetosphere-ionosphere system. Over the last decade, local convection measurements with incoherent scatter radars (ISRs) and more extended observations with drift meters onboard polar-orbiting satellites have been successfully complemented by global-scale observations with the coherent SuperDARN HF radars. Merging data from these instruments into a single set allows one to create a more reliable high-latitude convection pattern than could be produced by any individual data set. This is evident from the fact that the above instruments typically measure convection at distinctly different magnetic latitudes and/or magnetic local times.

While considering data from various convectionmonitoring instruments, one has to be sure that the data are compatible. In this respect, there are several difficulties,

Correspondence to: R. A. Drayton

(rad626@mail.usask.ca) stemming from the different spatial and temporal resolutions of the instruments. For example, ISRs measure plasma flow in F-region areas of $\sim 10 \mathrm{~km}$ in diameter with temporal resolution of $1-5 \mathrm{~min}$. The SuperDARN radars measure the line-of-sight (1-o-s) velocity with spatial and temporal resolutions of $\sim 45 \times 100 \mathrm{~km}$ (at typical F-region ranges) and $\sim 7$ s respectively, but the raw data are then merged into one block to produce a convection map under the assumption of a stable convection pattern over $2 \mathrm{~min}$. Because of the above differences, one would inevitably encounter differences between convection estimates from instruments operating simultaneously, even for observations in the same area of the high-latitude ionosphere. Indeed, recent comparisons of joint SuperDARN and ISR convection observations (Milan et al., 1999; Davies et al., 1999, 2000; Xu et al., 2001; Danskin, 2003) showed overall consistency but with noticeable data spread; for some events, almost perfect agreement was reported (Davies et al., 1999; Danskin, 2003) while for others significant differences were obvious (Xu et al., 2001; Danskin, 2003). These findings are in agreement with earlier ISR-HF radar comparisons by Villain et al. (1985) and Ruohoniemi et al. (1987).

It is not clear how satellite drift meter measurements compare against various ground-based convection measurements, because systematic inter-comparisons have not been reported in the past. Baker et al. (1990) compared the Goose Bay 1-o-s velocities with the DMSP ion drifts for one pass and showed that the radar velocities were close to the ion drifts (their Fig. 3). Xu (2003) selected 40 DMSP passes over the Saskatoon-Kapuskasing radar pair field of view and showed that both the merge (Greenwald et al., 1995) and Map Potential (Ruohoniemi and Baker, 1998) techniques give convection estimates in agreement with the DMSP cross-track ion drifts. Xu (2003) noticed that for large electric fields, the SuperDARN velocities were somewhat smaller than concurrent DMSP ion drifts, but no further investigation of the reason for these differences was undertaken. 
Clearly, an assessment of joint convection data obtained for various simultaneously operating systems would improve knowledge on the quality of the global convection pattern specification.

In this paper, we undertake a systematic assessment work on DMSP and SuperDARN convection measurements. We consider DMSP ion drifts and SuperDARN convection at the raw data level, namely we compare the cross-track DMSP ion drifts (this component is measured most reliably) and the SuperDARN 1-o-s velocities. For such a comparison, we do not make any assumption on the variation of the HF velocity with the azimuth (typically it is assumed to be of the cosine type), radar data filtering and post-processing is not involved so that one would expect the best agreement, as the only reason for differences could be the different spatial and temporal resolutions of the instruments, provided the F-region irregularities do move with the ExB velocity.

\section{Approach to the comparison and event selection}

We consider routine SuperDARN 1-o-s data gathered in the standard mode of operation at various locations in the Northern and Southern Hemispheres and DMSP ion drift data averaged over $4 \mathrm{~s}$. We remind the reader that in the standard mode each SuperDARN radar scans sequentially through 16 beam directions over either 1 or 2 min with a dwelling time in each beam position of 3 or $7 \mathrm{~s}$. For each beam position, echo power, Doppler velocity and spectral width are produced in 75 radar cells $45 \mathrm{~km}$ apart, starting from a range of $180 \mathrm{~km}$. The procedures for determining these parameters were described by Villain et al. (1987). Only measurements for which the echo power was more than $3 \mathrm{~dB}$ were considered in this study; most echoes were significantly stronger than this threshold. We only considered echoes with a spectral width of less than $500 \mathrm{~m} / \mathrm{s}$. In addition, echoes with an uncertainty in velocity determination of more than $150 \mathrm{~m} / \mathrm{s}$ were not considered. An error in the velocity fit was accepted as the uncertainty of its determination. Such restrictions to the data set helped to eliminate untypical echoes.

For the DMSP data, we considered 4-s averaged crosstrack ion drift component values measured by the ion drift meter (IDM) onboard the satellite. The IDM is designed to work in predominately $\mathrm{O}^{+}$plasma. When the percentage of $\mathrm{H}^{+}$or $\mathrm{He}^{+}$in the plasma increases above $15 \%$, the IDM is compromised and the data are not reliable. For this reason, each 4-s averaged data point is assigned a quality tag of 1 (measurement is reliable), 2 (measurement is questionable, use with caution), 3 (measurement is poor), or 4 (measurement quality is undetermined). Quality tag assignment is based on the presence of data within a $4 \mathrm{~s}$ interval, plasma density, and the portion of $\mathrm{O}^{+}$in the plasma. Data points assigned a poor quality tag were discarded in this analysis. For some events, a number of points with the quality flag specified as "undetermined" were still accepted if the spatial variation of the ion drift along the satellite track was smooth so that these points seemed to be very consistent with the ones of good quality. We also did not consider those events for which there was a transition of the DMSP drift polarity along the pass near the area of comparison because for such cases the velocity differences can easily be explained by different spatial resolutions of the instruments. Originally, we allowed various degrees of misalignment between the DMSP crosstrack direction and the SuperDARN radar beam, but the final statistics included only those measurements for which the difference was less than $5^{\circ}$.

Although the DMSP satellites are on polar orbits and the SuperDARN radars operate continuously, the identification of joint satellite/radar events is not an easy task. In the standard mode of operation, every SuperDARN radar scan starts exactly at the beginning of each minute (one minute scan) or at the beginning of every two minute interval (two minute scan). Certainly, one would not have a perfect match of radar and satellite measurements in terms of time. We selected the criterion for the proximity of the radar and satellite measurements in terms of time as the time difference between the measurements to be less than one (two) minute; this is consistent with 1-(2-)min inherent resolution of the SuperDARN convection maps.

One would certainly not expect a perfect match of the DMSP and radar measurements in terms of space. The DMSP satellite sampled every $\sim 7.5 \mathrm{~km} / \mathrm{s} \times 4 \mathrm{~s}=30 \mathrm{~km}$ while the size of a radar cell at a range of $\sim 1440 \mathrm{~km}$ from the radar, which is the average slant range for the 1-o-s velocities considered in this comparison, is $\sim 45 \mathrm{~km} \times 80 \mathrm{~km}$. The slant range is the distance from the radar to the center of the radar cell. It was assumed that the echo height was $300 \mathrm{~km}$. To compare the radar and satellite data, the following procedure was implemented. First, the DMSP ion drift data were assigned to corresponding footprints of the satellite at a height of $300 \mathrm{~km}$. For mapping along the magnetic field lines, the IGRF model was used. Then, for every selected radar cell with echo power stronger than $3 \mathrm{~dB}$ and spectral width less than $500 \mathrm{~m} / \mathrm{s}$, the DMSP points separated from the center of the radar cell by not more than $45 \mathrm{~km}$ were identified. Typically, at least 3 DMSP points were available. These were averaged to obtain the DMSP ion drift, and the standard deviation of measurements was considered as an estimate of the uncertainty of the DMSP ion drift. Only points with a standard deviation less than $150 \mathrm{~m} / \mathrm{s}$ were considered. The selected separation of $45 \mathrm{~km}$ is comparable with the azimuthal extent of a radar beam. The above assumptions imply that the DMSP data were actually averaged over $12-16 \mathrm{~s}$ versus 3 or $7 \mathrm{~s}$ for SuperDARN, the data can be up to $2 \mathrm{~min}$ apart in terms of time, and the effective spatial resolution of the instruments is comparable.

There was another factor significantly limiting the number of joint DMSP - SuperDARN events. Typically, the satellites do not exactly cross the radars' beams perpendicularly. Figure 1 gives an example of DMSP F15 tracks in both hemispheres (mapped down to $300 \mathrm{~km}$ ) and the SuperDARN radars' FoVs between ranges of $400 \mathrm{~km}$ and $2800 \mathrm{~km}$ (at a height of $300 \mathrm{~km}$ ). Passes potentially useful for the comparison with radar observations are shown by thick lines. Clearly, 

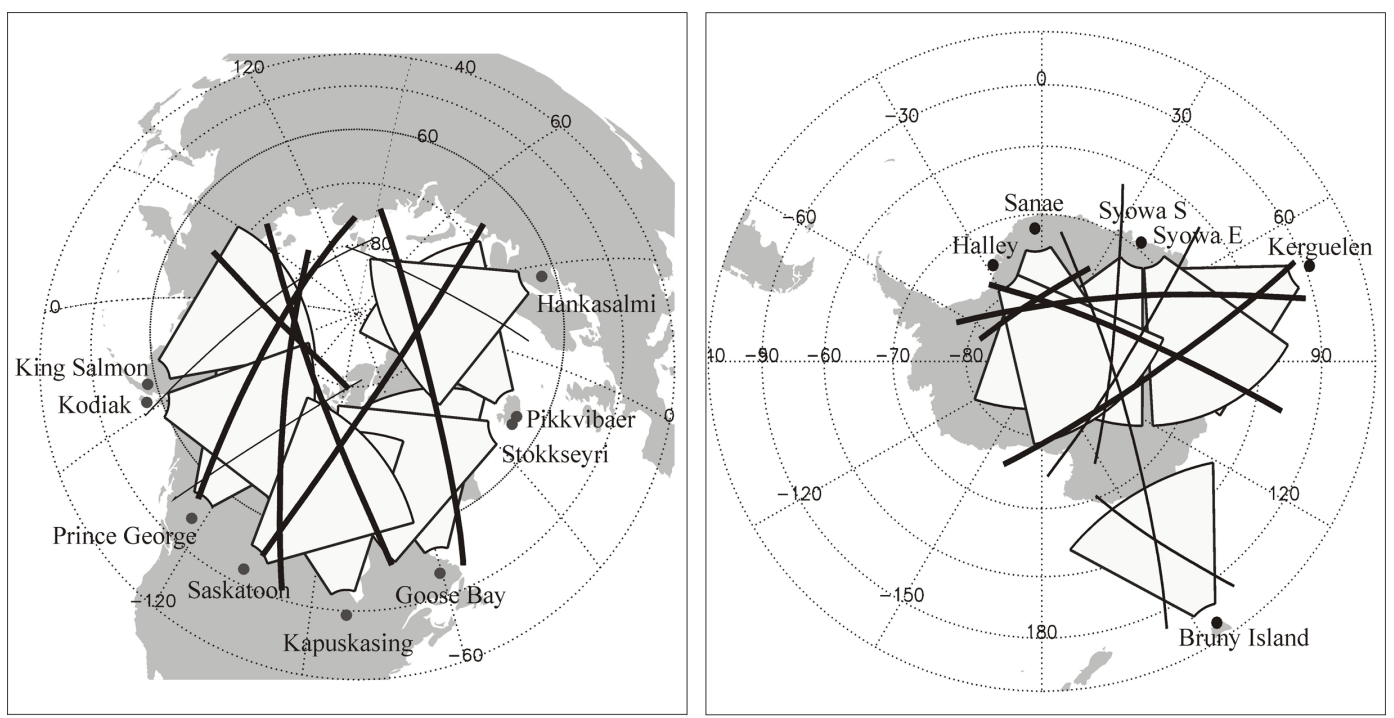

Fig. 1. SuperDARN radars' field of views between 400 and $2800 \mathrm{~km}$ in (a) Northern and (b) Southern Hemispheres and footprints (at a height of $300 \mathrm{~km}$ ) of DMSP F15 satellites. The trajectories represented by thick lines are potentially useful for cross-track ion drift velocity comparison with SuperDARN line-of-sight velocities.

the Kapuskasing and Goose Bay radars in the Northern Hemisphere and the Kerguelen and Tiger radars in the Southern Hemisphere can not be considered for comparison. In this study we considered 9 radars: Hankasalmi, Pykkvibaer, Stokkseyri, Saskatoon and Kodiak in the Northern Hemisphere and Halley, Sanae, Syowa-South, Syowa-East in the Southern Hemisphere. For the Kodiak radar, the DMSP satellite passed over the radar's field of view at two distinctly different range bands of approximately $1100 \mathrm{~km}$ and $2300 \mathrm{~km}$. We considered both ranges to explore a potentially important range effect.

Another limiting factor in building the joint database was the occurrence of SuperDARN echoes for a specific DMSP crossing. The satellites appear in the radars' FoVs every $\sim 100$ min but often there are no echoes or they are of poor quality. To achieve reasonable data statistics, observations over two-three years of each radar operation (1999-2002) were considered by sequential search through the SuperDARN quick-look plots. Our goal was to select about 20 passes (for each radar) with reasonable quality.

Figure 2 gives two examples of joint radar-satellite measurements. Here individual Stokkseyri 1-o-s velocities (colored boxes with the color scheme presented to the right of panel (c)) measured at various cells are plotted in geographic coordinates together with the DMSP F13 cross-track ion drifts over the radar's field of view. The time shown in the diagrams indicates the beginning of the two minute period of the SuperDARN scan. In both examples, the DMSP satellite crosses the radar's field of view at the approximate time of the scan. At 11:02 UT on 12 December 1999 the Doppler velocity varies relatively smooth in the area of comparison, panel (a), the velocities at corresponding data points (selected as described above) are very comparable and clus- ter around the bisector of ideal agreement, panel (b). For the event of 8 February, 2000 at 10:40 UT, the velocity map is much more patchy, and the velocities measured by the radar and satellite are not as consistent; two points are in good agreement, two other points lie below the bisector and the last three points are located above the bisector.

Figures 3 and 4 give statistical characteristics of radar echoes for which the comparison with DMSP measurements was carried out. There were echoes in most local time sectors (exception is the morning sector of 0400-0800 MLT) and magnetic latitudes $65^{\circ}-82^{\circ}$ in the Northern Hemisphere and $67^{\circ}-78^{\circ}$ in the Southern Hemisphere, Fig. 3. Typical echoes power was $\sim 19 \mathrm{~dB}$ S/N, Fig. 4a. A velocity span of 0 $1000 \mathrm{~m} / \mathrm{s}$ was achieved with the mean velocity magnitude of $\sim 330 \mathrm{~m} / \mathrm{s}$, Fig. 4b. The typical spectral width was $\sim 140 \mathrm{~m} / \mathrm{s}$, Fig. $4 \mathrm{c}$, and echoes were observed between $\sim 800 \mathrm{~km}$ and $2800 \mathrm{~km}$ with an average slant range of $1560 \mathrm{~km}$, Fig. $4 \mathrm{~d}$. These values are typical for F-region SuperDARN echoes.

\section{Comparison for the Stokkseyri radar}

To show how the radar-satellite data compare for an individual radar, we consider Stokkseyri-DMSP observations, Fig. 5. Figure 5 is a scatter plot of the Stokkseyri 1-o-s velocity versus the DMSP ion drift for 18 events. Only those radar and satellite measurements were considered for which the azimuth difference between the radar beam and the cross-track directions was less than $5^{\circ}$. Here, and for other radars as well, we imposed additional restriction: we considered only those radar echoes whose velocity magnitude was larger than $50 \mathrm{~m} / \mathrm{s}$. SuperDARN echoes with low velocities often show the presence of ionospheric and ground scattered (almost 



Fig. 2. Two examples of a SuperDARN/DMSP velocity comparison. (a) A Stokkseyri 1-o-s velocity map for a 11:02 UT with over-plotted DMSP cross-track ion drifts for the event of 12 December, 1999. (b) A scatter plot of the radar velocity versus the ion drift for the radar cells in panel (a) with a difference between the radar and satellite directions of less than $5^{\circ}$ and the difference in time of less than 2 min. Panels (c) and (d) show the same, but for the event of 8 February, 2002 at 10:40 UT. In both examples, the DMSP satellite crosses the radar's field of view at the approximate time of the scan.
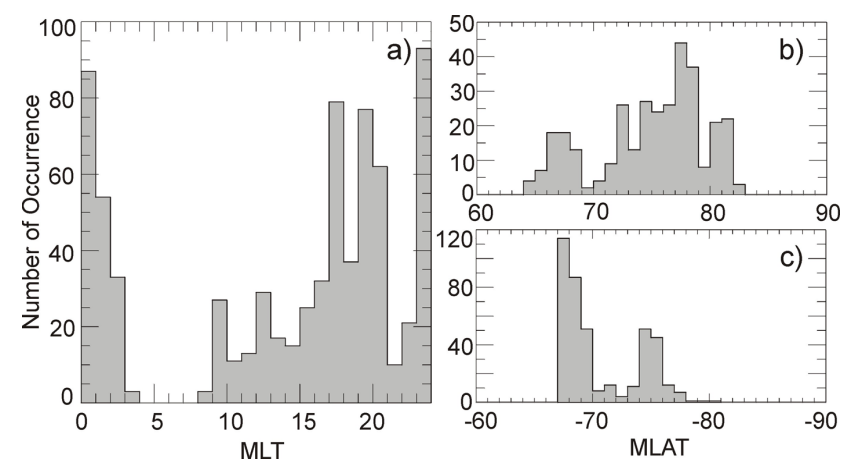

Fig. 3. Histogram distributions of the magnetic local times (panel (a)) and ACCGM magnetic latitudes (panels (b) and (c) for the Northern and Southern Hemispheres, respectively) for SuperDARN echoes selected for a comparison with DMSP measurements.

zero velocity) signals. By excluding echoes with velocities less that $50 \mathrm{~m} / \mathrm{s}$ we made sure that the signals we considered correspond to true ionospheric scatter.

A total of 53 points are available. One can see that the points are clustered around the bisector (dashed line) of perfect agreement; some of them are located significantly away from the bisector. Importantly, the points deviate both above and below the line of perfect agreement. For two points, in the second quadrant, the velocity polarities are different; similar points are present in other comparisons and they very likely correspond to very localized areas with completely different plasma flows and are therefore not considered in the statistics presented in Fig. 3, Fig. 4, or in determining the line of best fit. If one were to describe the scatter plot by a linear dependence, the line of the best fit (solid line) is $\mathrm{V}_{\mathrm{SD}}=0.73 \mathrm{~V}_{\mathrm{DMSP}}-35.5(\mathrm{~m} / \mathrm{s})$ implying a tendency for the Stokkseyri l-o-s velocity to be smaller than the DMSP ion drift. However, the effect is not recognizable in the plot unless large ion drifts $\mathrm{V}_{\mathrm{DMSP}}>800 \mathrm{~m} / \mathrm{s}$ are considered.

\section{Statistical assessment for all considered radars}

In Fig. 6 we present statistics for all 9 radars by applying the same criteria as for the Stokkseyri comparison of Sect. 3 . Totals of 746 points in 209 events are available. Figure 6 is consistent with the Stokkseyri results of Fig. 5; there is a reasonable agreement between the measurements and the points are spread around the bisector. The line of the best linear fit (solid line) is $\mathrm{V}_{\mathrm{SD}}=0.72 \mathrm{~V}_{\mathrm{DMSP}}+3.37(\mathrm{~m} / \mathrm{s})$ which is close to the one for the Stokkseyri radar. We should say that other radars showed some variability in the slope of the best fit line; Table 1 summarizes the findings. The best agreement with DMSP was found for the Syowa-East radar, not only 



Fig. 4. The histogram distributions of the SuperDARN radar (a) echo power, (b) velocity magnitude, (c) spectral width and (d) slant range for all events selected for a comparison with DMSP.

in terms of the slope of the best fit line $(\mathrm{S}=0.87)$, but also in terms of the data spread characterized by the correlation coefficient $\mathrm{R}(\mathrm{R}=0.93)$. The worst agreement was found for the Halley radar, both in terms of the slope $(S=0.49)$ and the correlation coefficient $\mathrm{R}(\mathrm{R}=0.55)$. Low slope of the best fit line was also found for the Sanae radar. We notice that for both these radars the comparison was performed for relatively low ranges of $<1200 \mathrm{~km}$. We assessed the quality of satellite-radar data agreement for intermediate and far radar ranges by splitting the data set into three groups, $<1200 \mathrm{~km}$, $1200-2000 \mathrm{~km}$, and $>2000 \mathrm{~km}$. We found that the agreement is the best for the intermediate ranges. The Kodiak radar data alone show better agreement for high ranges of $\sim 2300 \mathrm{~km}$ as compared to low ranges of $\sim 1100 \mathrm{~km}$.

\section{Discussion}

The SuperDARN/DMSP velocity comparison presented in this study shows, on a statistical basis, that in spite of different methods of plasma flow measurements, in space and from the ground, the velocities are fairly consistent in a broad sense. There is some data spread, but it can be explained by the time differences in measurements and different spatial and temporal resolutions of the instruments. We have already demonstrated in Fig. 2 that the general consistency of the data is much better if the flow is spatially uniform. To illustrate the importance of the flow stability in terms of time, we present observations at Syowa East, Antarctica on 4 March, 2001, Fig. 7. Figure 7a shows the 1-o-s velocity map for the scan 17:48 UT over-plotted with DMSP veloc-

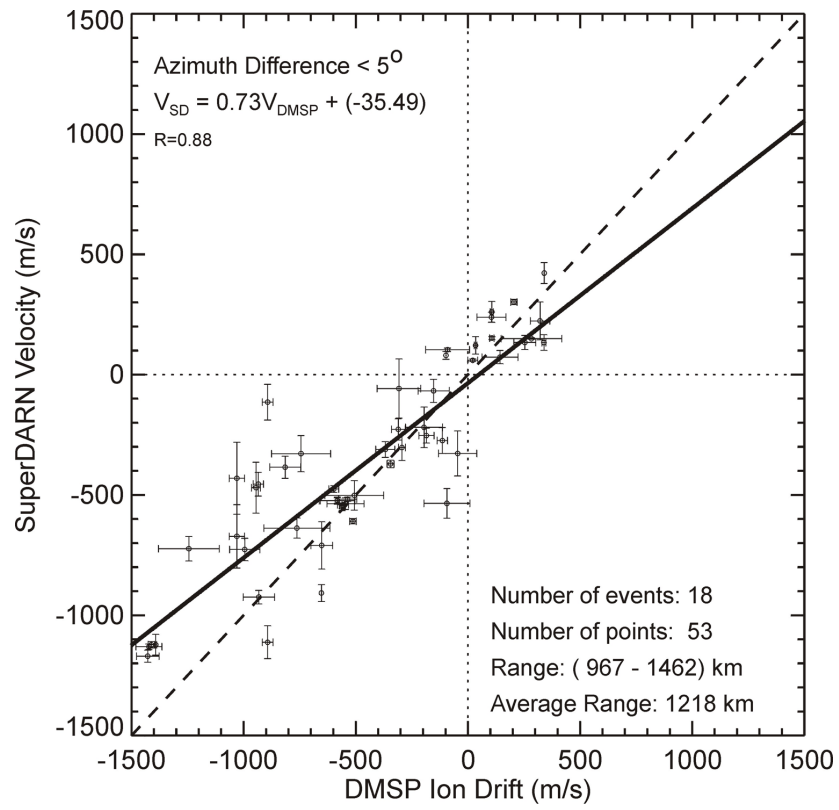

Fig. 5. A scatter plot of the Stokkseyri l-o-s velocity versus the DMSP cross-track ion drift for 18 joint events at radar ranges of $\sim 1000-1500 \mathrm{~km}$.

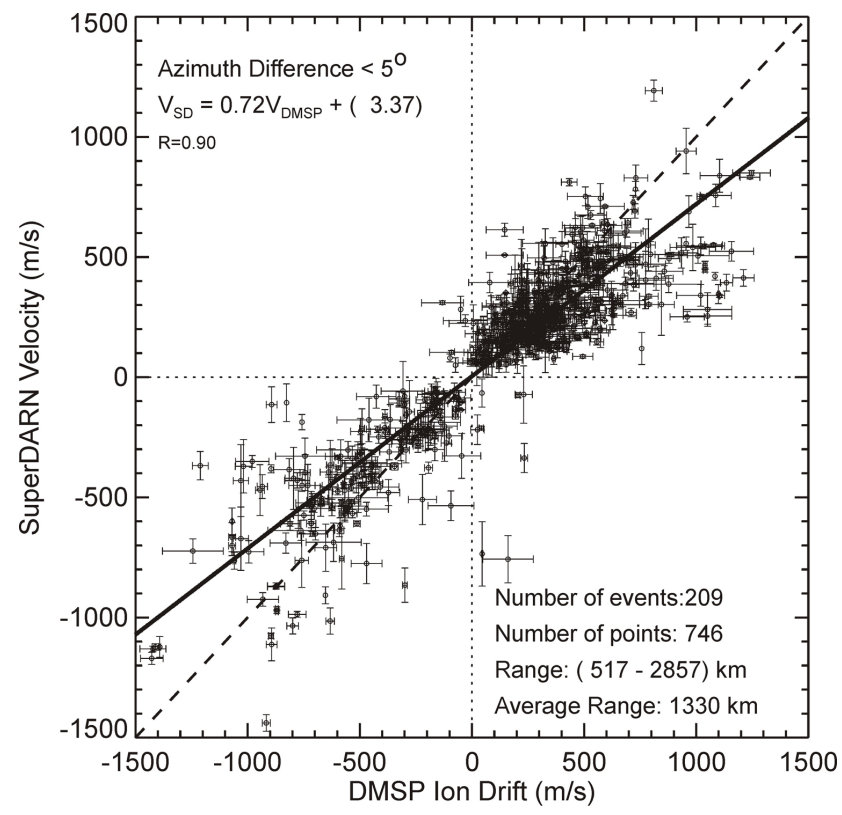

Fig. 6. The same as in Fig. 5 but for 9 radars: Hankasalmi, Pikkvibaer, Stokkseyri, Saskatoon, Kodiak, Halley, Sanae, SyowaSouth and Syowa-East and various radar ranges.

ity vectors. This scan was 4 min earlier than the scan for which the comparison with the DMSP data was performed (at 17:52 UT). The DMSP data were plotted on this panel for the convenience of viewing and have been omitted in panels (b) and (c). Figures $7 \mathrm{~b}$ and c show the Sanae data for scans at 17:52 and 17:54 UT. One can notice that in the area of the comparison, the 1-o-s velocities were generally smaller at 
Table 1. Information on number of events and points available, typical ranges, and the slope of the best fit line between SuperDARN and DMSP velocities for various radars

\begin{tabular}{llllll}
\hline Radar & Events & Points & Range $(\mathrm{km})$ & Slope & $\mathrm{R}$ \\
\hline Halley & 32 & 168 & $517-742$ & 0.49 & 0.55 \\
Sanae & 19 & 85 & $967-1147$ & 0.48 & 0.79 \\
Kodiak (Low) & 20 & 62 & $832-1327$ & 0.6 & 0.81 \\
Syowa South & 22 & 71 & $1012-1372$ & 0.79 & 0.76 \\
Stokkseyri & 18 & 53 & $967-1462$ & 0.73 & 0.88 \\
Syowa East & 21 & 87 & $967-2047$ & 0.87 & 0.93 \\
Pykkvibaer & 21 & 64 & $1327-1957$ & 0.62 & 0.87 \\
Saskatoon & 22 & 56 & $1732-2857$ & 0.58 & 0.77 \\
Hankasalmi & 17 & 51 & $1672-2137$ & 0.59 & 0.82 \\
Kodiak (High) & 17 & 49 & $1957-2542$ & 0.74 & 0.83 \\
All & 209 & 746 & $517-2857$ & 0.72 & 0.9 \\
\hline
\end{tabular}
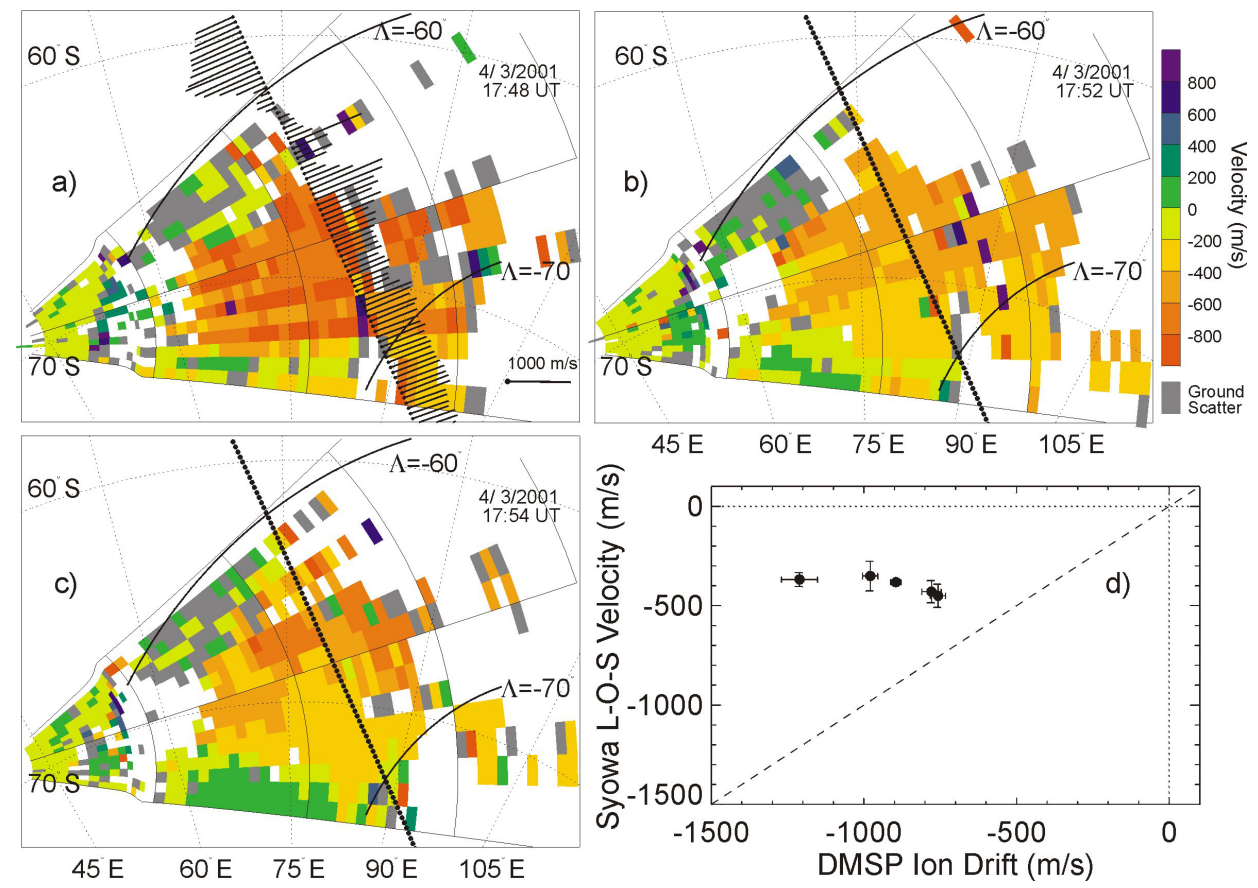

Fig. 7. (a)-(c) Syowa-East 1-o-s velocity maps for 17:48, 17:52 and 17:54 UT and the DMSP cross-track ion drift observed between $\sim 17: 49$ and 17:53 UT for the event of 4 March 2001. Panel (d) is a scatter plot of the radar velocity versus DMSP ion drift for the points in panel (b) with the difference between the radar and satellite directions of less than $5^{\circ}$ and the difference in time of less than 2 min.

17:52 UT (more light color) and larger again at 17:54 UT, meaning that significant temporal variations of the velocity had occurred. Since the time difference between the radar and satellite measurements was of the order of $120 \mathrm{~s}$, one would expect lower radar velocity than the DMSP velocity, and the poor agreement of the radar and satellite data shown in Fig. 7d is not a surprise.
Importantly, the comparison performed in this study included various radars of the SuperDARN network; the radars use the same principle of measurements, but their hardware and on site observational conditions vary. The comparison was also performed for various radar ranges so that all possible modes of radio wave propagation were considered. Significant coverage of magnetic latitudes and magnetic local time sectors was achieved. All the above means that the 
DMSP and SuperDARN 1-o-s velocities can be merged into one data set, provided that both instruments show reasonably smooth spatial and temporal variations. Such an approach is currently under development.

We noticed a minor tendency for the SuperDARN velocities to be smaller than the DMSP ion drifts. Similar conclusions were drawn from a comparison of SuperDARN data with incoherent scatter radar (Xu et al., 2001) and CADI ionosonde $(\mathrm{Xu}, 2003)$ measurements. We should say that this tendency is easier detected if velocities larger than 500 $800 \mathrm{~m} / \mathrm{s}$ are considered; if one includes only DMSP velocity magnitudes $<500 \mathrm{~m} / \mathrm{s}$, the slope of the best fit line is 0.80 . The total amount of such points is more than the number of points with large velocities (513 points versus 233 ) so that the significance of the SuperDARN "underestimation" effect is difficult to evaluate. Moreover, for the fast plasma flows, the data spread is somewhat enhanced for all comparisons so that a targeted investigation of large-velocity data needs to be performed. Unfortunately, such events occur rarely, and we leave this task for a separate study.

The explanation of the tendency for SuperDARN velocities to be less than DMSP ion drifts seems to be difficult. One possibility is that, while we assumed that the electric field is mapped down from the satellite height of $\sim 840 \mathrm{~km}$ to $300 \mathrm{~km}$ without any attenuation, this might not be correct if the small-scale electric fields are involved (Kelley, 1989). The effect can be especially significant for the events with patchy and highly variable convection patterns. Though we did not consider obvious events of this category, some minor convection variations could actually originate from partial shielding of the high-altitude electric field. Another possibility is the SuperDARN ionospheric echo contamination with the ground scattered signals. This effect cannot be identified by looking at FITACF data that we used in this study; a completely new approach with data processing of the full spectra is required which is beyond the scope of the present study. We attempted to check the quality of the SuperDARN spectra for some of the events with large DMSP velocity and strong discrepancy. Unfortunately, we are not able to draw a definite conclusion. For some events, the SuperDARN autocorrelation functions were not of great quality (for quality of the autocorrelation function see Villain et al. (1987)). For several other events, a strong ground scatter component was found; this could have affected the 1-o-s velocity. For some of the points, the quality of DMSP data was questionable, as the data quality flag changed along the path.

Another factor that might be of importance for understanding the larger SuperDARN-DMSP differences at high DMSP drifts is the degree of the azimuthal difference between the radar and satellite directions of measurements. This is especially important for observations at large angles with respect to the flow, which is typical for many radars. Perhaps, this notion can be supported by deterioration of the radarsatellite data agreement at larger radar ranges of the comparison. We found the data clustering was $\mathrm{R}=0.92$ at ranges $1200-2000 \mathrm{~km}$ and $\mathrm{R}=0.84$ at ranges $>2000 \mathrm{~km}$. This is generally expected since the radar localization of the echoing region deteriorates at large ranges, especially when one and half propagation mode is involved.

To explore the effect further, we attempted to relax the $5^{\circ}$ misalignment requirement. The results were very similar to the one presented in Fig. 6 except the data spread was more significant. For example, for $10^{\circ}$ misalignment, the line of best linear fit is $\mathrm{V}_{\mathrm{SD}}=0.73 \mathrm{~V}_{\mathrm{DMSP}}+3.05(\mathrm{~m} / \mathrm{s})$. We should note that the error in the alignment can be both positive and negative so that one would not expect a trend of smaller $\mathrm{Su}$ perDARN 1-o-s velocity as compared to the DMSP ion drift, unless the statistics are too small. We feel that our statistics are large enough and the observed trends are not originated from errors in the direction calculations.

The good agreement between the DMSP ion drifts and SuperDARN F-region velocities contrasts strongly with disagreement of the ion drifts and SuperDARN E-region velocities (Koustov et al., 2005). For the E region echoes, low velocities were expected from the previous VHF observations since the electrojet irregularities may travel with the velocity significantly different from ExB. For example, the irregularity velocity along the flow is close to the ion-acoustic speed. Luckily, the majority of SuperDARN radars observe mostly perpendicular to the electrojet; because of this, chances to get echoes with ion-acoustic speed from the E-region are not very high, even at very short ranges of $<500 \mathrm{~km}$. On the other hand, we might expect some E-region contamination, especially for the low-range comparisons at Halley and Sanae (ranges $<1000 \mathrm{~km}$ ). We investigated several events for the Halley radar but did not find clear signatures of the E-region contamination so that the question remains open.

The comparison presented in this paper does not mean that SuperDARN 1-o-s velocity measurements can be simply merged with the DMSP ion drifts to produce a joint convection map. Our comparison has been done for periods for which both instruments had the best chances to be compatible. We identified a number of other events with significant differences, including opposite polarity of the velocities. We noticed that this happens when the SuperDARN echoes are patchy or changing in time, and/or when the DMSP drift measurements showed strong variability within the radars' FoV. For such events, the spatial and temporal averaging are the major factors leading to the discrepancies.

\section{Conclusions}

In this paper we showed that for more than 200 DMSP passes over nine various SuperDARN radars' field of view the DMSP cross-track ion drift agrees reasonably well with the line-of-sight velocity of the F-region SuperDARN echoes. The slope of the best linear fit line relating the SuperDARN and DMSP velocities is of the order of 0.7 with a tendency for SuperDARN velocities to be smaller. The comparison has been performed for conditions with smooth temporal and spatial variations on the plasma flow according to both instruments; for strong variations, more significant differences were sometimes observed. The results imply that the DMSP 
ion drift velocities with relatively smooth profiles over the trajectory can be merged with the concurrent SuperDARN F-region velocities to produce a joint convection map.

Acknowledgements. We acknowledge the support of the national funding agencies that made possible continuous operation of the SuperDARN radars considered in this study. This work has been supported by NSERC (Canada) grant to AVK. Critical comments by $\mathrm{M}$. Pinnock are appreciated.

Topical Editor M. Pinnock thanks G. Provan and another referee for their help in evaluating this paper.

\section{References}

Baker, K. B., Greenwald, R. A., Ruohoniemi, J. M., Dudeney, J. R., Pinnock, M., Newell, P. T., Greenspan, M. E., and Meng, C.I.: Simultaneous HF-radar and DMSP observations of the cusp, Geophys. Res. Lett., 17, 1869-1872, 1990.

Danskin, D. W.: HF backscatter from the $\mathrm{F}$ and $\mathrm{E}$ regions, $\mathrm{PhD}$ Thesis, U of Saskatchewan, Saskatoon, Canada, 2003.

Davies, J. A., Lester, M., Milan, S. E., and Yeoman, T. K.: A comparison of velocity measurements from the CUTLASS Finland radar and the EISCAT UHF system, Ann. Geophys., 17, 892903, 1999,

SRef-ID: 1432-0576/ag/1999-17-892.

Davies, J. A., Yeoman, T. K., Lester, M., and Milan, S. E.: A comparison of $\mathrm{F}$ region ion velocity observations from the EISCAT Svalbard and VHF radars with irregularity drift velocity measurements from the CUTLASS Finland HF radar, Ann. Geophys., 18, 589-594, 2000,

SRef-ID: 1432-0576/ag/2000-18-589.

Greenwald, R. A., Baker, K. B., Dudeney, J. R., Pinnock, M., Jones, T. B., Thomas, E. C., Villain, J.-P., Cerisier, J.-C., Senior, C., Hanuise, C., Hunsuker, R. D., Sofko, G., Koehler, J., Nielsen, E., Pellinen, R., Walker, A. D. M., Sato, N., and Yamagishi, H.: DARN/SuperDARN: A global view of the dynamics of highlatitude convection, Space Sci. Rev., 71, 763-796, 1995.
Kelley, M. C.: The Earth's Ionosphere, Academic Press, San Diego, California, 1989.

Koustov, A. V., Danskin, D. W., Makarevitch, R. A., and Gorin, J. D.: On the relationship between the velocity of E-region HF echoes and ExB plasma drift, Ann. Geophys., accepted, 2005.

Milan, S. E., Davies, J. A., and Lester, M.: Coherent HF radar backscatter characteristics associated with auroral forms identified by incoherent radar techniques: A comparison of CUTLASS and EISCAT observations, J. Geophys. Res., 104, 22 591-22 604, 1999.

Ruohoniemi, M. and Baker, K. B.: Large-scale imaging of highlatitude convection with Super Dual Auroral Radar Network HF radar observations, J. Geophys. Res., 103, 20 797-20 811, 1998.

Ruohoniemi, J. M., Greenwald, R. A., Baker, K. B., Villain, J.-P., and McCready, M. A.: Drift motions of small-scale irregularities in the high-latitude F region: An experimental comparison with plasma drift motions, J. Geophys. Res., 92, 4553-4564, 1987.

Villain, J.-P., Caudal, G., and Hanuise, C.: A SAFARI-EISCAT comparison of $\mathrm{F}$ region small-scale irregularities and the ion drift, Ann. Geophys., 90, 8433-8443, 1985.

Villain, J. P., Greenwald, R. A., Baker, K. B., and Ruohoniemi, J. M.: HF radar observations of $E$ region plasma irregularities produced by oblique electron streaming, J. Geophys. Res., 92, 12 327-12 342, 1987.

$\mathrm{Xu}, \mathrm{L}$.: SuperDARN-derived plasma convection: Comparison with other data and application to field-aligned current measurements, $\mathrm{PhD}$ Thesis, U of Saskatchewan, Saskatoon, Canada, 2003.

Xu, L., Koustov, A. V., Thayer J., and McCready, M.: SuperDARN convection and Sondrestrom plasma drift, Ann. Geophys., 19, 749-759, 2001,

SRef-ID: 1432-0576/ag/2001-19-749. 